\title{
Does Health Insurance Coverage or Improved Quality Protect Better Against Out-of- Pocket Payments? Experimental Evidence from the Philippines
}

\author{
Natascha Wagner ${ }^{1}$, Stella Quimbo ${ }^{2}$, Riti Shimkhada ${ }^{3}$, John Peabody ${ }^{4}$
}

\begin{abstract}
This paper explores whether health insurance coverage or improved quality at the hospital level protect better against out-of-pocket payments. Using data from a randomized policy experiment in the Philippines, we found that interventions to expand insurance coverage and improve provider quality both had an impact on out-of-pocket payments. The sample consists of 3,121 child-patient patient observations across 30 hospitals either at baseline in 2003/04 or at the follow-up in 2007/08. Compared to controls, interventions that expanded insurance and provided performance-based provider payments to improve quality both resulted in a decline in out-of-pocket spending (21\% decline, $p$-value $=0.061$; and $24 \%$ decline, $p$ value $=0.017$, respectively). With lower out-of-pocket payments for hospital care, monthly household spending on personal hygiene rose by 0.9 (p-value=0.026) and 0.6 US\$ (pvalue $=0.098)$ under the expanded insurance and provider payment interventions, respectively, amounting to roughly a 40 to $60 \%$ increase relative to the controls. With the current surge for health insurance expansion in developing countries, our study suggests paying increased and possibly, equal attention to supply-side interventions will have similar impacts with operational
\end{abstract}

\footnotetext{
${ }^{1}$ Corresponding author. Development Economics Research Group. International Institute of Social Studies of Erasmus

University Rotterdam, Kortenaerkade 12, 2518 AX The Hague, The Netherlands.

${ }^{2}$ University of the Philippines, School of Economics, Diliman, Quezon City, Philippines and Philippine Competition

Commission.

${ }^{3}$ University of California, Los Angeles

${ }^{4}$ QURE Healthcare, University of California, San Francisco and University of California, Los Angeles
} 
simplicity and greater provider accountability.

Keywords: Philippines, health insurance, health care quality, universal health coverage, outof-pocket payments, $R C T$

Acknowledgements: The Quality Improvement Demonstration Study was funded by the US National Institutes for Child Health and Human Development through an R01 grant (HD042117).

Disclaimer: The views and opinions expressed in this article are those of the authors and do not necessarily reflect the official policy or position of the funding agency or any institution the authors are affiliated with. 


\section{Introduction}

Out-of-pocket payments for health care are still the major source of health care financing in most developing countries. Such medical expenses have the potential to further increase the burden of poverty with an estimated 150 million people who fall into poverty due to catastrophic health care expenditures every year (McIntyre et al. 2006; van Doorslaer et al. 2006; Xu et al. 2007). To better protect against unexpected illness and unplanned health care expenditures, a range of health sector financing reforms are implemented throughout developing countries. These public policy interventions range from the introduction of community-based health insurance (Jakab and Krishnan 2001; Smith and Sulzbach 2008; Mebratie et al. 2015), to health equity funds for the poor (Flores et al. 2013), improved access to quality health care through set user fees (Litvack and Bodart 1993), or the introduction of social health insurance programs for a large portion of the (so far uninsured) population (Limwattananon et al. 2015; Sparrow et al. 2013b; King et al. 2009; Thornton et al. 2010). A detailed literature review about health care financing reforms and their impact on access, utilization of care and financial protection can be found in the online appendix A1 [INSERT LINK TO ONLINE APPENDIX A1].

Yet, there is an important dearth in understanding and a lack of studies that contrast the impact of demand-side, insurance-based reforms versus supply-side, provider payment reforms. This adds to policy uncertainty over how best to provide financial protection to the poor. In this study, we contrast a demand- and a supply-side intervention implemented in 30 public hospitals in the central regions of the Philippines to assess which one achieves a greater reduction in outof-pocket expenditures for incidences of child hospitalization. The randomized health policy experiment, known as the Quality Improvement Demonstration Study (QIDS), was conducted between 2003 and 2008. QIDS was a large-scale community level intervention with a combined 
catchment area of an estimated one million households. The 30 hospitals participating in the study were randomly assigned into a control site and two different policy intervention sites, one expanding access to health insurance and the other intervention incentivizing hospital staff through bonus payments. The overarching objective of QIDS was to evaluate the effects of these policies on the health status of children, through utilization and quality channels. The focus was on children who were hospitalized due to pneumonia and diarrhea as these diseases are among the leading causes of morbidity and mortality among Filipino children (Department of Health 2011). Large returns to these conditions were expected since they do not reflect routine hospitalizations but urgent cases.

We estimate the impact of the QIDS demand-side insurance intervention compared to the supply-side incentive intervention along five dimensions: (i) out-of-pocket payments for hospital services, (ii) the costs of medical treatment inside and outside the hospital, and (iii) household spending on disease prevention. To analyze overall expenditure patterns we further look at (iv) total household health expenditures independent of the incidence of hospitalization under study and whether (v) there is reallocation of household spending. We show that both interventions reduced out-of-pocket payments for child hospitalizations by at least $20 \%$ without any discernable statistical differences ( $p$-value $=0.825$ ). Moreover, we found that monthly household spending on personal hygiene rose by $0.9(p$-value $=0.026)$ and $0.6(p$-value $=0.098)$ US\$ under the expanded insurance and provider payment intervention, respectively.

The remainder of the paper is organized as follows: The contextual background and design of the project are presented in Section 2. Section 3 introduces the data. Section 4 introduces the two empirical specifications, the linear fixed effects and Poisson fixed effects model. Results are presented in Section 5. Section 6 concludes.

\section{Setting}




\subsection{Contextual background}

In the Philippines, improving access to care has been a priority policy concern since the Health Sector Reform Agenda was launched in 1999 through the National Health Insurance Program, more commonly known as PhilHealth. PhilHealth's mandate is to provide universal health insurance coverage. According to their own reports PhilHealth covers $88 \%$ of the population (PhilHealth 2015). Yet, based on national surveys the actual coverage rate seems smaller: The 2008 National Demographic and Health Survey indicates that $47.8 \%$ of surveyed households had at least one household member covered by PhilHealth further revealing that about 58\% of the poorest children with acute respiratory illness receive medical treatment and only about $37 \%$ of the poorest children with symptoms of diarrhea get oral rehydration therapy (NDHS 2008).

In PhilHealth's aim to provide financial protection to the poor, the insurer targets selected population groups, i.e. government-employees, indigent individuals, retirees, and overseas workers. To afford more financial protection, among these groups, the insurance premiums vary, for example, an average formally employed individual pays a premium of 3,370 pesos per person and year. This corresponds to roughly 76.5 US\$ applying the peso-US\$ exchange rate of 0.0227 , which was observed in January 2015. The insurance covers the individual, spouse, and dependent children under 21 years. Indigent individuals are sponsored by the national and local governments, which pay PhilHealth premiums amounting to 2,400 pesos ( $\approx 54.4$ US\$) per household and year. The basic benefit package covers inpatient care but not outpatient care or medications purchased outside of the hospital.

PhilHealth finances only about $10 \%$ of the overall personal health care spending in the Philippines (NSCB 2013). Despite expanding coverage and subsidized premiums aimed towards the poor, the Philippine National Health Accounts (2011) indicate that out-of-pocket 
expenditures remain the most dominant form of health-care financing, accounting for $52.7 \%$ of total health-care expenditures in 2011 (NSCB 2013).

\subsection{QIDS project}

The Quality Improvement Demonstration Study (QIDS), a 5-year project, was undertaken to potentially benefit an estimated one million households. Launched in 2001, community level randomization was applied to 30 public hospitals that were organized into matched blocks of three and randomly assigned to either one of two interventions and a control group. The

matching was done based on demand and supply characteristics of the hospitals such as population, average household income, number of beds, average case load, PhilHealth accreditation and insurance coverage of the households. The hospitals are geographically dispersed, with some completely isolated because they are located on different islands. Thus, spill-overs between the experimental groups and the control groups were minimized. It is also unlikely that households go to different hospitals for health care services since this would entail even longer commuting time and higher transportation costs.

Two interventions were implemented and financed by PhilHealth involving alternative methods of making payments in public hospitals. In general, hospitals that are PhilHealth accredited provide insurance coverage to their members either on a reimbursement basis or through a direct deduction on the patient's hospital bill. The amount of insurance coverage is pre-determined and based on the severity of the case, i.e., whether ordinary, intensive, or catastrophic. In addition, PhilHealth compensates the attending physicians of accredited hospital. The compensation is a daily rate accounting for the level of training of the physician, i.e. 105 pesos (2.38 US\$) for general practitioners and 150 pesos (3.41 US\$) for specialists. Further details can be found in the PhilHealth Board Resolution No. 324-00. 
Building on PhilHealth's insurance coverage, the first intervention targets the demandside. It is known as “Access”. It sought to reduce out-of-pocket payments by (i) ensuring that households in Access sites are PhilHealth covered by increasing enrollment efforts, and (ii) automatically classifying pediatric patients in Access hospitals as “intensive” cases. To achieve increased enrollment, QIDS staff was deployed as “policy navigators” to local governments since the latter could subsidize PhilHealth premiums of their indigent constituents. The QIDS study sites were relatively poor, with average household income estimated at $60 \%$ below the national levels (Quimbo et al. 2011). Hence, the most effective way of increasing PhilHealth enrollment in Access sites was through premium subsidies by local governments. This was known as the PhilHealth "Sponsored Program”. Effectively indigenous households were eligible for fully subsidized premiums and zero co-payments since costs were covered by the insurance. Prior to the experiment, we verified that insurance amounts would on average cover hospital bills for "intensive" cases. The expected effect of the Access intervention was to increase PhilHealth insurance coverage such that out-of-pocket payments for children aged 5 years and below are substantially reduced.

The second intervention targeted the supply side and is known as the "Bonus" intervention. We introduced a system of monitoring quality of care and paid bonuses for quality improvements. Quality of physician services was measured through clinical vignettes, openended paper cases of hypothetical patients that simulate and measure actual clinical practice. Selected physicians were required to complete vignettes for three target conditions: child pneumonia, diarrhea, and a common dermatological condition. To complete each vignette, physicians were asked questions intended to capture diagnostic skills. Note that vignettes are an accredited approach for assessing physician quality (Dresselhaus et al, 2000; Peabody et al. 2000; Peabody et al. 2004). 
The overall score for each Bonus hospital was an index that combined the hospital's average of individual physician vignette scores, case load, and patient satisfaction scores. The weights attached to each of these three components were 70,10 , and $20 \%$, respectively. Patient satisfaction was measured using the Patient Satisfaction Questionnaire 18 (PSQ-18), a short form of the Patient Satisfaction Questionnaire III (Marshall and Hays 1994). PSQ-18 covers seven domains of quality: general satisfaction, technical quality, interpersonal skills, communication, finances, amount of time spent with the provider, and access to care. Bonus hospitals that met predefined cut-off scores for a particular quarter were eligible for bonuses. This was implemented by automatically applying the specialist rate in computing PhilHealth payments for all physicians. While the experiment was conducted, a substantial majority of the physicians in Bonus hospitals were generalists (72\%). On average, we estimate that bonuseligible physicians received a 5\% increase in income during the experiment. Bonus payments were given quarterly from 2004 to 2007. The physicians received the bonuses with their salaries. No targeting or recruitment efforts were required to make the Bonus intervention operable. The existing system for administering payments could be used for the additional payments.

Bonus payments are expected to affect out-of-pocket payments indirectly. While patients still have to pay for the treatment, bonus payments provide incentives to doctors to perform better by making more accurate diagnoses, prescribing the appropriate tests and treatments and not aiming at extra income by suggesting additional outside the hospital treatments (James et al. 2009). When physicians better manage patients, expenditures can fall (Peabody et al. 2010) and length of stay can be reduced (Carey, Sheth and Braithwaite 2005). In QIDS sites, we found that the relationship between costs and quality is U-shaped (Peabody et al. 2010). At sufficiently low initial quality levels, improvements in quality can reduce out- 
of-pocket payments: at below 60\% vignette scores, every 10 percentage point increase in quality is associated with an average $20 \%$ decline in charges.

Throughout this paper we refer to the "Access" intervention as "intervention A" and the “Bonus" intervention as "intervention B". The hospitals in the control group, referred to as "C sites”, continued with the existing policies and practices. The three types of randomly selected hospitals in $\mathrm{A}, \mathrm{B}$, and $\mathrm{C}$ sites constitute the primary sampling unit for the evaluation of the QIDS interventions.

For the evaluation of the interventions data were collected before and after the two health policy reforms were introduced. Data for this paper were obtained from two QIDS sources: (i) a patient exit survey and (ii) a follow-home survey 4-6 weeks after the child patient was discharged from the hospital. The patient exit and household surveys were conducted in 2003/04 and 2007/08. By the time the second follow-up survey commenced, interventions had been in place for close to 2 years. The patient exit surveys were administered among the parents of child patients up to the age of 5 years. A total of 6,042 children were surveyed. During the patient exit survey detailed information about the out-of-pocket expenditures, those incurred inside and outside the hospital, were collected. Among the surveyed children, pneumonia and diarrhea patients were eligible for the follow home survey. Altogether, 3,183 children were revisited at home of whom we have complete information for 3,121 children. Lost observations due to missing information amount to less than $2 \%$ of the overall sample. The follow home surveys in both rounds provide a detailed socioeconomic profile of the household including information on spending patterns independent of the child hospitalization. Ethical approval for the study was obtained from the Committee on Human Research of the University of the Philippines.

\section{Data}


The sample consists of 3,121 household observations, each of which had a child-patient in one of the 30 QIDS hospitals either at baseline in 2003/04 or at the follow-up in 2007/08. The observations are equally split across the three types of sites: In the A sites we have information on 1,036 patients; B sites comprise 1,055 observations; and the remaining 1,030 patients frequented the $C$ sites. In the first survey round, a total of 1,393 child patients participated; the follow-up survey covered 1,728 patients.

Basic descriptive statistics illustrating the features of the sampled child patients and their households are presented in Table 1 . Of the total number of children $43.5 \%$ are girls. The children are, on average, slightly older than one and a half years and stay 4 days in the hospital. By design, the sample is equally split among pneumonia and diarrhea patients. Households have about six members and at least one child below the age of 14 for every working adult. On average, the households have a monthly per capita income of 1,054 pesos ( $\approx 23.9$ US\$). As the primary sampling unit for the randomization is hospitals, we test for the balancing of the baseline child and household characteristics across the three hospital groups. Comparing child and household characteristics at baseline for each of the three cohorts, we find that the two intervention groups and the control site are comprised of children with statistically similar characteristics at the 5\% significance level in all the 30 comparisons. However, maternal education and per capita family income are slightly higher at baseline in the insurance expansion group compared to the control group ( $p$-value $=0.064$ and 0.058 , respectively). No significant differences are found for the pay-for-performance group ( $p$-value $>0.1$ ). Moreover, child characteristics such as age, gender and severity of disease are similar across all three groups ( $p$-value $>0.1$ ). Yet, to account for child and household heterogeneity in the analysis, we jointly include these variables as controls in our empirical model.

We assess five sets of outcomes: (i) out-of-pocket expenditures, (ii) expenditures incurred inside versus outside the hospital, (iii) total household expenditures on health care 
(independent of the child hospitalization) (iv) household expenditures associated with disease prevention such as water and sanitation as well as (v) household expenditures on non-health items including food and other household consumption expenditures. The five sets of outcome variables are all measured in terms of pesos spent.

We define out-of-pocket payments as all direct outlays of cash that are incurred because of the child hospitalization under study. They include the total medical spending associated with the hospitalization as well as transportation and food expenditures related to the hospitalization.

Concerning the costs incurred inside and outside the hospital we observe the following: In the Philippines, like many developing countries, services and goods needed by a patient may not be completely available within a single facility. Referrals to other facilities, say, for diagnostic procedures or services of a specialist, are frequent. The same is true for purchases of drugs, which can be done outside the hospital if the prescribed drugs are not available in the hospital pharmacy. Poorly funded hospitals may not be equipped with basic diagnostic machines such as X-rays and tend to have pharmacies that are not well stocked. Arguably then, expanded insurance coverage, which means increased resources at the hospital, would imply increased availability of goods and services and the reduced need for patients to purchase goods and services outside the hospital. Of course, there could be other reasons for patients preferring to purchase goods and services outside the facility. Prices inside the facility could be higher even with insurance or doctors could prescribe drugs that are not available inside the hospital but rather in a pharmacy outside the hospital where they have a financial interest (James et al. 2009). Most insurance claims against PhilHealth are, however, for purchases inside the hospital, rather than outside the hospital. Therefore, we distinguish between two types of illness-related medical spending: those incurred inside and outside the hospital.

The household-level consumption expenses that are not directly related to the child 
hospitalization such as overall health expenditures, expenditures associated with disease prevention and consumption expenditures are denoted in per capita and month terms. The household health expenditures include drugs and medicines, hospital room charges, medical and dental charges, and other medical goods and supplies. There is the possibility of conflation between the costs associated with the child hospitalization under study and the per capita health expenditures that are (presumably) not linked to the hospitalization: The former information was collected at patient exit and is likely to be an accurate representation of the actual costs incurred. The latter was collected as part of the household survey that was administered 4-6 weeks after patient discharge. Findings associated with per capita household health expenditures need to be assessed keeping this caveat in mind.

Our measure of spending on disease prevention includes the following components: (i) toilet/bath soap, body deodorants, lotion, tissue paper, (ii) drinking water, water used for bathing and washing and (iii) laundry and laundry soap. We also study non-health related expenditures. Food consumption expenditures include the consumption of beverages and are likely to be a lower bound of food consumption as the majority of the households under study self-consume their own production and only buy foodstuff on the market and report expenditures for food, which they do not grow themselves. Education expenditures comprise matriculation fees, allowance for family members studying away from home, as well as books and school supplies. Finally, expenditures for durable goods comprise those for clothing, furnishing, dinnerware and house maintenance.

The descriptive statistics for the outcome variables show that out-of-pocket payments for the hospitalization of the child patient amounted to 2,212 pesos $(\approx 50.2$ US\$) on average (Table 2). Average out-of-pocket payments are slightly higher than total medical spending associated with the hospitalization because the former also cover transportation and food expenditures related to the hospitalization. Total spending is mainly made up of costs incurred 
inside the hospital, an average of 1,422 pesos $(\approx 32.3$ US\$). Expenditures for health services used outside the hospital amount to an average of 677 pesos ( $\approx 15.4$ US\$). Since we consider actual hospitalizations we are not concerned about zeros in out-of-pocket expenditures.

Next, we turn to household level expenditures not including the costs of the hospitalization of the child patient under study. Per capita health expenditures are 88 pesos $(\approx 2.0$ US\$), accounting for $8.6 \%$ of the total monthly expenditure per individual. Keep in mind that there might be some conflation between the hospitalization under study and per capita household health expenditures. On average, per capita health expenditures are of similar range as the per capita costs for toiletries, water and sanitation that amount to 82 pesos ( $\approx 1.9$ US\$). Taken together, monthly health expenditures and those for personal hygiene make up for $16 \%$ of the total monthly per capita expenditures. Relative to these 170 pesos constituted by the regular health care and preventive care spending, the out-of-pocket payments for the child hospitalization amount to roughly 13 times the monthly expenditures per household member.

We also looked at other expenditure groups in the household. Monthly per capita expenditures for food consumption including beverages amount to 552 pesos ( $\approx 12.5$ US $\$$ ). This rather moderate amount relative to overall costs is consistent with spending by the poor who rely on home production (rather than market goods) to cover their basic nutritional needs (Folbre, 1984; Bardhan and Udry, 1999; de Janvry and Sadoulet, 2002). The poverty level of these households is further demonstrated by the low per capita spending for education and durable goods such as clothing, furnishing, dinnerware and house maintenance, amounting to 28 and 59 pesos $(\approx 0.6$ and 1.3 US\$) on a per capita and month basis, respectively. For comparison, per capita monthly costs for transport and communication average about 56 pesos, which is similar to the amount for durable goods.

To assess the impact of the A and B interventions on outcome variables, we compared the two treatment and the control groups after the implementation of the intervention testing for 
differences in means (Table 2). Three patterns stood out. First, the direct comparison of means reveals that out-of-pocket payments are roughly 450 pesos ( $\approx 10.2$ US\$) lower in both the A and B intervention sites compared to the controls ( $p$-value=0.000). Second, the out-of-pocket spending levels inside and outside of the hospital differ systematically across the three types of sites. In the control sites, expenditures outside the hospital are between 436 and 565 larger $(\approx 10.2$ US\$, $p$-value=0.000) whereas patients in either intervention sites spend more on services inside the hospital. The latter result is mainly driven by the B intervention. Third, overall health expenditures at the household level are lower for families residing in the intervention sites ( $p$ value $<0.010$ ). However, these lower health expenditures do not seem to be linked to changes in the expenditures for per capita monthly food consumption. Food consumption is on average, at the same level for households residing in all three sites given a significance level of $1 \%$. At the $5 \%$ significance level we fail to reject the equality of means in food consumption for B and C sites. Per capita monthly education expenditures and those for transport and communication are identical when comparing average levels in the two intervention areas with those in the control group ( $p$-value $>0.1)$.

\section{Empirical Specification}

A multivariate analysis is performed to identify the impact of the two QIDS interventions on the identified expenditure categories. The effects of the two interventions are estimated in a difference-in-difference specification that compares the changes in the costs of care in intervention sites with the corresponding changes in control sites over the two rounds of data collection. We employ a fixed effects model that allows us to control for the unobserved heterogeneity at the hospital level such as location and stable regional conditions. Inflation dynamics are taken care of by the year (national trend) and the hospital fixed effects (regional 
disparities). We allow the error term to be clustered across individuals that are treated at the same hospital.

While the linear fixed effects model is our benchmark model, we also employ a fixed effects Poisson model with cluster-bootstrapped standard errors as robustness test. The Poisson model better encompasses our expenditure variables, which do not follow a normal distribution but are censored at zero and skewed to the right due to some severe cases where large health spending occurred (Sparrow et al. 2013a). Although our dependent variables are not count data in the strict sense, the Poisson model has shown to be well suited for consistent estimation in the context of health costs (Buntin and Zaslavsky, 2004). A detailed description of the empirical models and methodological decisions can be found in the online appendices A2 and A3 [INSERT LINK TO ONLINE APPENDICES A2 AND A3].

\section{Results}

The findings from the linear fixed effects model show that intervention A reduces outof-pocket payments by 558 pesos $(\approx 12.7$ US $\$$, $p$-value=0.072)(Table 3$)$. Intervention $B$, which appears to be more effective, reduces out-of-pocket payments on average by 638 pesos $(\approx 14.5$ US\$, $p$-value $=0.028)$. Comparing the coefficient estimates associated with Intervention $\mathrm{A}$ and B we find that both interventions are similarly effective in reducing out-of-pocket payments ( $p$ value=0.797) .

These fixed-effects estimates are consistent with the Poisson regression results (Table 3, Column 2). While the magnitude of the coefficient estimates from the Poisson model is not directly comparable with that of the linear model, we observe a similar statistically significant and negative relationship between the two interventions and out-of-pocket payments. Calculating the incidence rate ratio, which is obtained by applying the exponential function to the Poisson coefficient, we see that the out-of-pocket payments are lower $(<1)$ for patients 
residing in the intervention areas. For intervention A, the incidence rate ratio is 0.79 (=exp(0.241)) indicating that expanded health insurance reduces out-of-pocket payments by $21 \%$ ((10.79)*100; $p$-value=0.061). Intervention B reduces out-of-pocket payments by about $24 \%$ $(=(1-\exp (-0.274)) * 100 ; p$-value=0.017). The magnitudes of the Poisson incidence rate ratios are in line with the coefficient estimates from the linear model and the average out-of-pocket spending across the three sites (Table 2). Comparing the average out-of-pocket payments of 2,212 pesos ( $\approx 50.2$ US\$) to the reduction in out-of-pocket payments of 558 pesos (638 pesos) induced by intervention A (B), this corresponds to a 30\% (29\%) decline in out-of-pocket spending. Thus, we present consistent evidence that in the Philippines out-of-pocket spending declined due to increased insurance coverage. Second, we show that provider-based incentives can similarly reduce the economic burden of out-of-pocket spending.

The total medical spending resulting from the child hospitalization is also lower in intervention areas with the point estimates significant at 9.9 and $11.7 \%$ for interventions $\mathrm{A}$ and B, respectively. From the Poisson regressions, we obtain more precise estimates confirming that patients who utilized intervention A and B hospitals face lower overall expenditures ( $p$ value $=0.040$ and 0.027 , respectively). Although we cannot determine which intervention is overall less costly because the coefficient estimates are statistically identical ( $p$-value=0.607). But we can say that the QIDS supply side intervention, which improves the quality of care through a pay-for-performance scheme, reduces out-of-pocket and total medical spending as much as the expanded health insurance policy.

To further disentangle the effects on out-of-pocket payments, we separately looked at expenditures incurred inside and outside the hospital. Results show that the reductions in expenditures are driven by lower expenditures outside the hospital (Table 3, Columns 5 to 8). Spending inside the hospital is not significantly affected by the interventions.

However, expenditures incurred outside the hospital decrease by 436 pesos ( $\approx 9.9$ US\$) 
for intervention A and 565 pesos ( $\approx 12.8$ US\$) for intervention B. Consistent with the findings for out-of-pocket payments, outside hospital expenditures are similarly affected by the two interventions; the coefficient estimates associated with interventions A and B are similar ( $p$ value $=0.431$ ). Further support for this finding comes again from the Poisson model. For intervention A, we observe that outside hospital expenditures decrease by $44 \%$ (=) $1-\exp (-$ 0.578))*100). Similarly, for intervention B outside hospital expenditures decrease by 55\% $(=(1-\exp (-0.799)) * 100)$. Again, the coefficient estimates are not significantly different from each other ( $p$-value=0.449). This reduction in outside hospital spending could suggest a reduction in demand as more services are now directly utilized within the hospital. The combined findings about inside and outside hospital expenditures clarify that the two interventions did not increase inside hospital spending but concomitantly reduced expenditures outside the hospital.

Finally, we examined to what extent the reduced out-of-pocket payments resulting from interventions A and B induced changes in other household expenditures. We find that per capita health expenditures that are not linked to the hospitalization under study are lower in intervention sites (Table 4, Columns 1 and 2). Expanded insurance reduces per capita monthly health expenditures by 75 pesos ( $\approx 1.7$ US\$); the bonus intervention reduces per capita health expenditures by 47 pesos per month $(\approx 1.1$ US $\$)$. Again, the Poisson model supports these results and indicates a reduction in overall health expenditures by almost 60\% ((1-exp(0.885))*100) as a consequence of Intervention A. Intervention B similarly reduces health expenditures, namely by $42 \%((1-\exp (-0.546)) * 100)$. As indicated in section 3 there is the possibility that the reported per capita health expenditures are conflated with the costs of the hospitalization under study. Despite the fact that we collected information on per capita health expenditures in an independent household survey, we acknowledge that households might add up the costs. 
We also looked at the impacts of the two interventions on expenditures that are associated with disease prevention, i.e. the combined costs for toiletries, water and sanitation (Table 4, Columns 3 and 4). Households benefitting from interventions A and B spend more on personal hygiene with per capita monthly spending on these products rising by 41 ( $\approx 0.9$ US\$, $p$-value $=0.026)$ and 27 pesos $(\approx 0.6$ US $\$, p$-value $=0.098)$, respectively. While these increases in spending on hygiene appear small, in our study sites they are sufficient to purchase additional clean water. With an incidence rate ratio between 1.40 and 1.61, the Poisson model confirms these findings revealing that the interventions A and B increase spending on water and hygiene by roughly 40 to $60 \%$ relative to the control group ( $p$-value $=0.025$ and 0.094 , respectively). Equality of the coefficient estimates cannot be rejected ( $p$-value $=0.341$ ) indicating that interventions A and B similarly trigger a resource reallocation towards preventive care. In light of the analyzed diseases, namely diarrhea and pneumonia the results on personal hygiene spending are of particular interest. Diarrhea is a water-related disease that is most common for individuals who do not have access to clean water for drinking, cooking and personal hygiene. Similarly, the immune system of children drinking low quality water is impaired making severe conditions such as pneumonia more likely to develop. At the time of the experiment, the average price of a one-liter bottle of water was about 12 to 25 pesos in the capital region, Metro Manila (Magtibay 2004). Thus, a 27 to 41 peso increase per capita in spending on clean water could have been used by households to purchase an additional 1 to 3 liters of bottled water per month. The additional 3 liters are equivalent to $8 \%$ of the monthly requirement of clean water for children aged 1 to 3 years (Food and Nutrition Board 2004).

We further considered the impact of the interventions on household expenditures for items such as food consumption, education, and durable goods (Appendix, Table A.1). Across specifications and expenditure categories we do not find significant intervention effects. The freed up resources from reduced out-of-pocket payments do not appear to be re-allocated to 
these other expenditure groups.

We note two potential limitations of our study. First, we only establish policy impacts for those children who are sick and admitted to a hospital. We argue, however, that our interventions potentially benefited the population at large. Intervention A aimed at increasing enrollment in health insurance, in particular enrollment of vulnerable populations. The quality improvement aimed at with intervention B is for the benefit of all patient types.

Second, we focus our analysis exclusively on children with diarrhea and pneumonia. These are severe conditions among children and the leading causes of morbidity and mortality (see Section 2). UNICEF and the World Health Organization (2013) acknowledge that diarrhea and pneumonia are the two leading causes of preventable child death and have put in place an integrated global action plan and a working group to end child death from these conditions by 2025. Our research contributes to these efforts. We abstain from drawing conclusions for adults but observe that out-of-pocket expenditures related to severe conditions in children are a burden that affects the entire household.

\section{Conclusion}

The QIDS experiment provided a unique opportunity to contrast the effectiveness of a demand- and supply-side intervention in providing financial risk protection to poor households for instances of child hospitalization. Both the expanded insurance and quality incentive intervention had lower out-of-pocket payments compared to the controls. There was a $21 \%$ (24\%) decline in out-of-pocket spending due to intervention A (B) with no statistical difference between the two interventions. Similarly, total medical expenditures were lower in intervention areas compared to controls. The reductions in medical expenditures were driven by lower expenditures outside the hospital (no differences seen in inside hospital expenditures comparing 
interventions to control). This suggests that all services can be obtained inside the hospitals without incurring additional out-of-pocket payments outside the hospital.

Moreover, intervention households reported lower overall curative health expenditures over the preceding six months indicating that the households may be more aware of preventive measures and more inclined to employ preventive care when they are financially protected against adverse health events. This was further supported by increased spending on preventive health care as captured by purchase of clean water and hygiene-related expenditures. This suggests that freed-up household resources due to reduced out-of-pocket payments may have long-term implications on household health as households seem to spend these resources on health goods that prevent infectious diseases.

While we acknowledge that our results are context and design specific, we consider it as one of the biggest advantages of the study at hand to experimentally compare two different social policy interventions to protect the poor from high health care expenditures. Interestingly, we found similar impacts from both the demand- and the supply-side health care intervention with no significant differences between the two policies. As hypothesized, the insurance scheme reduced out-of-pocket payments. The finding highlights that it is possible to implement health insurance reforms in developing countries that lead to increased financial protection of the insured. This is a particularly important finding as existing research about out-of-pocket payments shows that health insurance does not necessarily lead to lower health spending at the household level due to moral hazard by the doctors and hospitals (Dutta and Husain, 2012; Yip and Hsiao, 2009; Hsiao, 2008). In addition, we find evidence indicating that improved quality due to provider-based incentives also protects households from the financial risk of illness. It appears that the QIDS pay-for-performance scheme improved the clinical skills of doctors thereby reducing unnecessary prescriptions of drugs and medical tests and thus reducing outof-pocket payments. The quality intervention, by reducing spending outside the hospital, 
arguably, also increases hospital accountability for service and health outcomes. The pathway for the provider-based intervention is improved quality for in and outpatient care.

The study at hand challenges the current surge for health insurance expansion in developing countries and suggests paying increased and possibly, equal attention to supply-side interventions. As demonstrated, supply-side interventions can have similar financial protection impacts but combined with operational simplicity and greater provider accountability. Since, health care providers can be expected to have structures in place for advancing salaries and bonus payments, they are an efficient conduit for administering the financial side of health

reforms. Targeting hospitals and their physicians implies that only a circumscribed number of individuals and institutions need to be collaborated with. In turn, for the insurance intervention to be effective, it was necessary to enroll households into PhilHealth. The potential set of insurees was considerably larger compared to the straightforward group of doctors working in PhilHealth accredited hospitals. Enrollment needed to be organized for the households outside a pre-defined institutional context. Moreover, given the relatively low income levels of most of the households in the target areas, they were eligible for premium subsidies, which involved local governments. The local governments needed to be reached out to with policy navigators and social marketing efforts implying additional costs of targeting.

Therefore, we argue for further advancing research on the impacts of both demand-side, insurance-based reforms and supply-side, provider payment reforms to quell the uncertainty over how best to provide financial protection to the poor.

\section{References}

Bardhan, P., C. Udry. 1999. Development Microeconomics. Oxford University Press: Oxford. Buntin, Melinda Beeuwkes, Alan M. Zaslavsky. 2004. Too much ado about two-part 
models and transformation? Comparing methods of modeling Medicare expenditures. Journal of Health Economics 23(3): 525-542.

Carey, Mark R., Heena Sheth, R Scott Braithwaite. 2005. A Prospective Study of Reasons for Prolonged Hospitalizations on a General Medicine Teaching Service. Journal of General Internal Medicine 20(2): 108-115.

de Janvry, Alain, Elisabeth Sadoulet. 2002. World Poverty and the Role of Agricultural Technology: Direct and Indirect Effects. Journal of Development Studies 38(4): 1-26. Department of Health. 2011. Ten (10) Leading Causes of Child Mortality By Age-Group (1-4, 5-9, 10-14) \& Sex, Philippines, 2009. Date accessed: May 5, 2014.

Dresselhaus, Timothy, John Peabody, Martin Lee, Ming Ming Wang, Jeff Luck.2000. Measuring compliance with preventive care guidelines - Standardized patients clinical vignettes and the medical record. Journal of General Internal Medicine 15(11): 782788.

Dutta, Mousumi, Zakir Husain. 2012. Use of hospital services and socio-economic status in urban India: Does health insurance ensure equitable outcomes? MPRA Paper No. 40055.

Flores, Gabriela, Por Ir, Chean R. Men, Owen O’Donnell, Eddy Van Doorslaer. 2013. Financial Protection of Patients through Compensation of Providers: The Impact of Health Equity Funds in Cambodia. Journal of Health Economics 32(6): 1180-1193. Folbre, Nancy. 1984. Household Production in the Philippines: A Non-Neoclassical Approach. Economic Development and Cultural Change 32(2): 303-330.

Food and Nutrition Board. 2004. Dietary Reference Intakes for Water, Potassium, Sodiu, Chloride, and Sulfate. Washington, DC: The National Academies Press.

Hsiao, William. 2008. When Incentives And Professionalism Collide. Health Affairs 27(4): 949-951. 
Jakab, Melitta, Chitra Krishnan. 2001. Community Involvement in Health Care Financing: Impact, Strengths and weaknesses-A Synthesis of Literature, Discussion paper for WHO Commission on Macroeconomic and Health. Washington, DC: World Bank. James, Chris, John Peabody, Orville Solon, Stella Quimbo, Kara Hanson. 2009. An Unhealthy Public Private Tension: The Impact of Physician Pharmacy Ownership on Prescribing Practices and Patient Spending, Health Affairs 28(4):1022-1033.

King, Gary, Emmanuela Gakidou, Kosuke Imai, Jason Lakin, Ryan T Moore, Clayton Nall, Nirmala Ravishankar, Manett Vargas, Martha María Téllez-Rojo, Juan Eugenio Hernández Ávila, Mauricio Hernández Ávila, Héctor Hernández Llamas. 2009. Public policy for the poor? A randomised assessment of the Mexican universal health insurance programme. The Lancet 373: 1447-1454.

Limwattananon, Supon, Sven Neelsen, Owen O'Donnell, Phusit Prakongsai, Viroj Tangcharoensathien, Eddy van Doorslaer, Vuthiphan Vongmongkol. 2015. Universal coverage with supply-side reform: The impact on medical expenditure risk and utilization in Thailand. Journal of Public Economics 121: 79-94.

Litvack, Jennie I., Claude Bodart. 1993. User fees plus quality equals improved access to health care: Results of a field experiment in Cameroon. Social Science \& Medicine 37(3): 369-383.

Magtibay, Bonifacio. 2004. Water refilling station: an alternative source of drinking water supply in the Philippines. 30th WEDC International Conference, Vientiane, Lao PDR.

Marshall, Grant N., Ron D. Hays. 1994. The patient satisfaction questionnaire short-form (PSQ-18). Rand Paper P7865.

McIntyre, Diane, Michael Thiede, Göran Dahlgren, Margaret Whitehead. 2006. What are 
the economic consequences for households of illness and of paying for health care in low- and middle-income country contexts? Social Science \& Medicine 62(4): 858865.

Mebratie, Anagaw, Robert A. Sparrow, Zelalem Y. Debebe, Degnet Abebaw Ejigie, Getnet Alemu, Arjun S. Bedi. 2015. The impact of Ethiopia’s pilot community based health insurance scheme on healthcare utilization and cost of care. ISS Working Paper 593, $1-46$.

NDHS. 2008. Philippines 2008 National Demographic and Health Survey -- Key Findings.

NSCB. 2013. Philippine National Health Accounts 2005-2011. National Statistics Coordination Board (NSCB).

Peabody, John, Jeff Luck, Peter Glassman, Timothy Dresselhaus, Martin Lee. 2000.

Comparison of Vignettes, Standardized Patients, and Chart Abstraction: A Prospective Validation Study of 3 Methods for Measuring Quality. JAMA 283: 1715-1722.

Peabody, John, Jeff Luck, Peter Glassman, Sharad Jain, Joyce Hansen, Maureen Spell, Martin Lee. 2004. Measuring the Quality of Physician Practice by Using Clinical Vignettes: A Prospective Validation Study. Annals of Internal Medicine 141(10): 771-780.

Peabody, John, Jhiedon Florentino, Riti Shimkhada, Orville Solon, Stella Quimbo. 2010. Quality Variation and its Impact on Costs and Satisfaction: Evidence From the QIDS Study. Medical Care 48(1): 25-30.

PhilHealth 2015. 1st Semester 2015 Stats and Charts.

Quimbo, Stella, John Peabody, Riti Shimkhada, Orville Solon. 2011. Evidence of a causal link between health outcomes, insurance coverage and a policy to expand access: Experimental data from children in the Philippines, Health Economics 20(5): 620630.

Smith, K., S. Sulzbach. 2008. Community-based health insurance and access to maternal 
health services: evidence from three West African countries. Social Science and Medicine 66 (12): 2460-2473.

Solon, Orville, John Peabody, K. Woo, Stella Quimbo, Jhiedon Florentino, Riti Shimkhada. 2009. “An evaluation of the cost-effectiveness of policy navigators to improve access to care for poor in the Philippines,” Health Policy, 92(1): 89-95. Sparrow, Robert, Ellen Van de Poel, Gracia Hadiwidjaja, Athia Yumna, Nila Warda, Asep Suryahadi. 2013a. Coping with the economic consequences of ill health in Indonesia. Health Economics.

Sparrow, Robert, Asep Suryahadi, Wenefrida Widyanti. 2013b. Social Health Insurance for the Poor: Targeting and Impact of Indonesia's Askeskin Program. Social Science \& Medicine, 96: 264-271.

Thornton, Rebecca, Laurel Hatt, Erica Field, Mursaleena Islam, Freddy Solís Diaz, Martha Azucena González. 2010. Social security health insurance for the informal sector in Nicaragua: a randomized evaluation. Health Economics. 19 (Issue Suplmenent 1): 181-206.

UNICEF and WHO. 2013. Ending Preventable Child Deaths from Pneumonia and Diarrhoea by 2025 - The integrated Global Action Plan for Pneumonia and Diarrhoea (GAPPD). WHO Press, Geneva.

van Doorslaer, Eddy, Owen O'Donnell, Ravi Rannan-Eliya, Aparnaa Somanathan, Shiva Raj Adhikari, Charu Garg, Deni Harbianto, Alejandro Herrin, Mohammed Nazmul Huq, Shamsia Ibragimova, Anup Karan, Chiu Wan Ng, Badri Raj Pande, Rachel Racelis, Sihai Tao, Keith Tin, Kanjana Tisayaticom, Laksono Trisnantoro, Chitpranee Vasavid, Yuxin Zhao. 2006. Effect of payments for health care on poverty estimates in 11 countries in Asia: an analysis of household survey data. The Lancet 368(9544): $1357-1364$. 
Wooldridge, Jeffrey. 2002. Econometric Analysis of Cross Section and Panel Data. MIT Press: Cambridge.

Xu, Ke, David Evans, Guido Carrin, Ana Mylena Aguilar-Rivera, Philip Musgrove, Timothy Evans. 2007. Protecting Households From Catastrophic Health Spending. Health Affairs 26(4): 972-983.

Yip, Winnie, William Hsiao. 2009. China's health care reform: A tentative assessment. China Economic Review 20(4): 613-619. 
Table 1: Descriptive statistics of control variables, the total number of observations is 3,121. Balancing of baseline characteristics across the two 


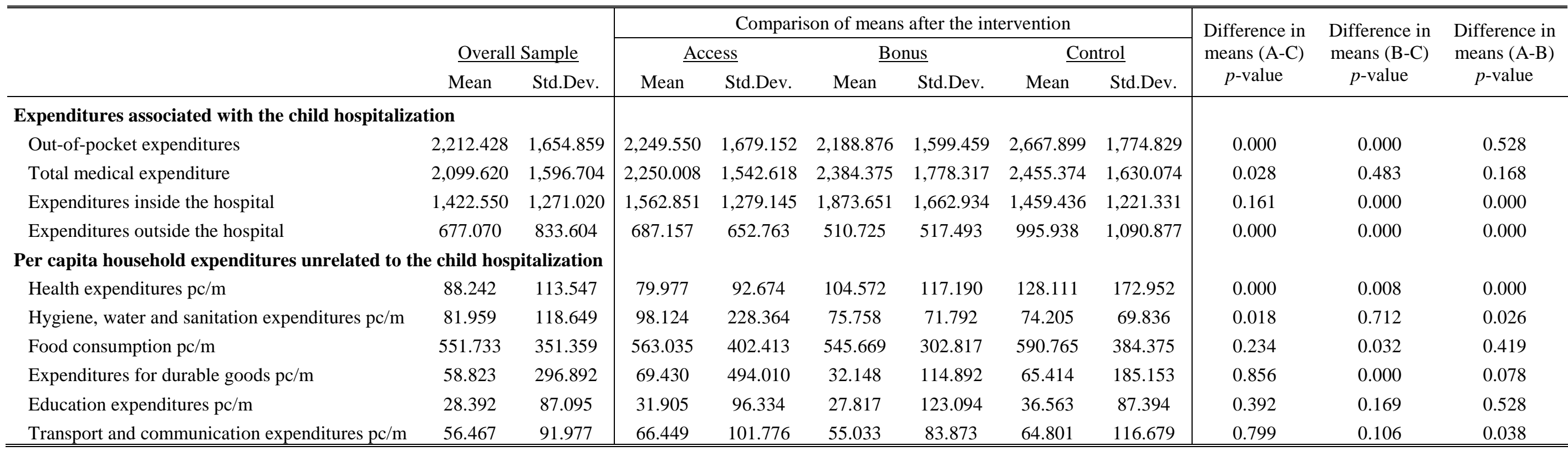

\footnotetext{
25 Table 2: Descriptive statistics of the outcome variables, the total number of observations is 3,121. "pc/m” refers to per capita and month at the
}

26 household level. For the variables "Health expenditures pc/m” and "Hygiene, water and sanitation expenditures pc/m” only 3,073 and 3,064

27 observations are available, respectively. Similarly, for the variables "Food consumption pc/m”, "Education expenditures pc/m” and "Expenditures

28 for transport and communication pc/m” only 3,044, 3,073 and 3,082 observations are available, respectively. Comparison of means across the three

29 groups, after the interventions are put in place, are presented in Columns 3 to 8 . The last three columns present the $p$-values of the associated

30 difference in means tests. 


\begin{tabular}{|c|c|c|c|c|c|c|c|c|}
\hline & \multicolumn{2}{|c|}{$\begin{array}{l}\text { Out-of-pocket } \\
\text { expenditures }\end{array}$} & \multicolumn{2}{|c|}{$\begin{array}{c}\text { Total medical } \\
\text { expenditures associated } \\
\text { with the hospitalization }\end{array}$} & \multicolumn{2}{|c|}{$\begin{array}{l}\text { Expenditures inside the } \\
\text { hospital }\end{array}$} & \multicolumn{2}{|c|}{$\begin{array}{l}\text { Expenditures outside the } \\
\text { hospital }\end{array}$} \\
\hline & OLS & Poisson & OLS & Poisson & OLS & Poisson & OLS & Poisson \\
\hline Access intervention & $\begin{array}{l}-558.043+ \\
(298.547)\end{array}$ & $\begin{array}{l}-0.241+ \\
(0.128)\end{array}$ & $\begin{array}{l}-559.629+ \\
(328.237)\end{array}$ & $\begin{array}{l}-0.289 * \\
(0.141)\end{array}$ & $\begin{array}{l}-123.365 \\
(335.488)\end{array}$ & $\begin{array}{l}-0.131 \\
(0.241)\end{array}$ & $\begin{array}{l}-436.264+ \\
(221.636)\end{array}$ & $\begin{array}{l}-0.578 * \\
(0.282)\end{array}$ \\
\hline Bonus intervention & $\begin{array}{l}-638.483 * \\
(276.763)\end{array}$ & $\begin{array}{l}-0.274 * \\
(0.115) \\
\end{array}$ & $\begin{array}{l}-413.067 \\
(255.464)\end{array}$ & $\begin{array}{l}-0.223 * \\
(0.101) \\
\end{array}$ & $\begin{array}{c}151.866 \\
(240.078)\end{array}$ & $\begin{array}{c}0.026 \\
(0.165) \\
\end{array}$ & $\begin{array}{l}-564.932 * \\
(211.426)\end{array}$ & $\begin{array}{c}-0.799 * * \\
(0.277)\end{array}$ \\
\hline Observations & 3,121 & 3,121 & 3,121 & 3,121 & 3,121 & 3,121 & 3,121 & 3,121 \\
\hline Hospitals & 30 & 30 & 30 & 30 & 30 & 30 & 30 & 30 \\
\hline FE & yes & yes & yes & yes & yes & yes & yes & yes \\
\hline
\end{tabular}

34 Table 3: Results for expenditures associated with the child hospitalization, namely (i) out-of-

35 pocket expenditures, (ii) the total medical expenditures associated with the hospitalization, (iii)

36 expenditures inside and (iv) outside the hospital. The following control variables are included:

37 Gender and age of the child, duration of stay, whether the child had pneumonia, maternal

38 education, per capita monthly income, household size, dependency ratio for 0-14 year olds and

$3965+$ year olds, round dummy. The standard errors of the linear model are clustered at the

40 hospital level, the standard errors of the Poisson model are cluster-bootstrapped at the hospital

41 level with 500 replications. $+/ * / * *$ indicates significance at the 10/5/1 percent level,

42 respectively.

43

44

\begin{tabular}{lcccc}
\hline \hline & \multicolumn{2}{c}{$\begin{array}{c}\text { Health expenditures per } \\
\text { capita/month }\end{array}$} & $\begin{array}{c}\text { Hygiene, water and } \\
\text { sanitation expenditures } \\
\text { per capita/month }\end{array}$ \\
\cline { 2 - 5 } Access intervention & OLS & Poisson & OLS & Poisson \\
\cline { 2 - 5 } & $-75.377^{* *}$ & $-0.885^{* *}$ & $41.472^{*}$ & $0.474^{*}$ \\
Bonus intervention & $(25.697)$ & $(0.235)$ & $(17.674)$ & $(0.211)$ \\
& $-46.810+$ & $-0.546^{*}$ & $27.413+$ & $0.333+$ \\
\hline Observations & $(26.400)$ & $(0.238)$ & $(16.018)$ & $(0.199)$ \\
Hospitals & 3,073 & 3,073 & 3,064 & 3,064 \\
FE & 30 & 30 & 30 & 30 \\
\hline
\end{tabular}

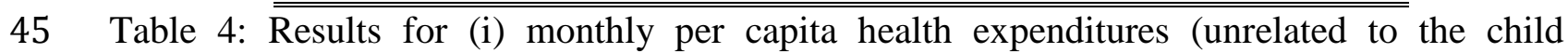

46 hospitalization), and (ii) monthly per capita hygiene, water and sanitation expenditures. For

47 further information on the control variables and the specifications compare the note of Table 3.

$48+/ * / * *$ indicates significance at the 10/5/1 percent level, respectively. 